\title{
Comparison of Orgasm Time Amongst Genitally Mutilated and Unmutilated Women
}

\author{
Matthew Chukwuma Michael \\ Department of Mathematics and Statistics \\ Delta State Polytechnic \\ Ogwashi-Uku, Delta State \\ megawaves4life@yahoo.com \\ Adigwe M. Isioma \\ Department of Mathematics and Statistics \\ Federal Polytechnic \\ Kaura Namoda, Zamfara State.
}

\begin{abstract}
Female genital mutilation is a topical issue in modern societies. In spite of health challenges that have been linked to the act, such belief as a strong/hyper sensitivity and promiscuity have enhanced a continuation of the act. This study compares the average time of orgasm between genitally mutilated and unmutilated women. The study sample is made up of 336 women in Ika North-East Local Government Area of Delta State. The Dummy Variable Regression Technique was applied. It was observed that Orgasm Time of mutilated women is 4.48 minutes less than that of their unmutilated counterparts in the average.
\end{abstract}

Keywords: Orgasm, Time, Genital Mutilation, Unmutilated Women, Ika North, Nigeria and Variables

Aims Research Journal Reference Format:

Matthew Chukwuma Michael \& Adigwe, M. Isioma (2018): Comparison of Orgasm Time amongst Genitally Mutilated and Unmutilated Women. Advances in Multidisciplinary \& Scientific Research Journal. Vol. 4. No.1, Pp17-18

\section{INTRODUCTION}

Genital mutilation in women is the act of removing or cutting off part of the genitalia of women. It is a permanent damage or non-medical removal of any part of the genital organ (UNICEF, 2013). In most cultures, the main target is the clitoris in order to reduce sensitivity and sexuality. Other cultures cut off the inner or outer labia. Some other cultures close the vulva (Abdulcadir, et al., 2016). The practice is rooted in gender inequality and attempts to control women's sexuality (Nahid \& Sharif, 2003). The health effects of female genital mutilation include recurrent infection, difficulty in urinating and passing menstrual flow, chronic pain, development of cysts, inability to get pregnant, complications during childbirth, and fatal bleeding (Abdulcadir, et al., 2016).

Health effects may also include vesico vaginal fistula (VVF). There has not been any recorded health benefit of genital mutilation in women (World Health Organization, 2017). The criticism and opposition of the practice is common among the medical field, and anthropologists, who have raised difficult questions about cultural relativism and the universality of human rights (Bettina, 2008). This study will compares the average orgasm time of mutilated and unmutilated women to ascertain if the damaged or removed part of the genitalia is responsible for sensitivity.

\section{THE METHOD}

The data for this study were gathered from 336 women out of a total of 91388 in Ika North-East Local Government Area (National Population Commission of Nigeria, 2009). Questionnaires were administered to the target respondents who, are mainly teachers, health workers and non-illiterate traders. All the communities in the study area were properly represented in the sample. The basic assumption is that the population is stationary relative to the 2016 census. 
The dummy variable regression Analysis was applied to data. The dummy variable regression model is:

$y_{i}=\alpha_{0}+\delta_{0} x_{i}+e_{i}$

where

$x_{i}=\left\{\begin{array}{l}1 \text { if the } i^{\text {th }} \text { women is not genitally mutilated } \\ 0 \text { if the } i^{\text {th }} \text { woman is genitally mutilated }\end{array}\right.$

Specifically, the dummy variable regression model for orgasm time and mutilation status is

Orgasm Time $=a_{0}+\delta_{0}$ (mutilation status $)_{i}+e_{i}$

Hence, the analytical model becomes

Orgasm T'me $=10,90-4.48(\text { mutilation status })_{l}+e_{2}$

From Equation 4 it is observed that the average Orgasm Time of unmutilated women is 4.48 minutes less than that of their mutilated counterparts. The model is significant at 0.05 level of significance with a $P$ - value of 0.003 and coefficient of determination of 0.67. A Variance Inflation Factor of 1.00 shows that Average Orgasm Time of unmutilated women is uncorrelated with the Average Orgasm Time of mutilated women. Hence, the model is a good fit.

\section{CONCLUSION}

The fact that Average Orgasm Time of unmutilated women is significantly less than that of their mutilated counterparts shows that the mutilated women are denied the full pleasure and sensitivity that should come with intercourse. This is actually an issue that bothers on fundamental human right. Considering that there is no health benefit of the act, it should be completely discouraged.

\section{REFERENCES}

1. Abdulcadir, J., Catania, L., Hindin, M. J., Say, L., Petignat, P., \& Abdulcadir, O. (2016, Nov). Female Genital Mutilation: A Visual Reference and Learning Tool for Health Care Professionals. Obstetrics and Gynecology., 128(5), 958 - 963. doi:10.1097/AOG.0000000000001686

2. Bettina, S.-D. (2008). From Health to Human Rights: Female Genital Cutting and the Politics of Intervention. American Anthropologist, New Series., 110(2), 225 - 236. doi:10.111/j.1548 - 1433.2008.00028

3. Nahid, F. T., \& Sharif, E. H. (2003, September). Female Genital Mutilation: have we made progress? International Journal of Gynecology and Obstetrics, 82(3), 251 - 261. doi:10.1016/S0020-7292(03)00229 - 7

4. National Population Commission of Nigeria. (2009). 2006 National Population Census. Retrieved from www.nationalpopulationcommission.ng.org.

5. UNICEF. (2013). Concluding Observations on the Seventh Periodic Report of the United Kingdom of Great Britain and Northern Ireland. United Nations Committee on the Elimination of All Form of Discrimination against Women (CEDAM).

6. World Health Organization. (2017, February). Female Genital Mutliation. Geneva: World Health Organization. 